\title{
Variation of calcium, copper and iron levels in serum, bile and stone samples of patients having different types of gallstone: A comparative study
}

\author{
Mustafa Khan $^{\mathrm{a}, *}$, Tasneem Gul Kazi ${ }^{\mathrm{a}}$, Hassan Imran Afridi ${ }^{\mathrm{a}}$, Sirajuddin ${ }^{\mathrm{a}}$, Muhammad Bilal ${ }^{\mathrm{a}}$, \\ Asma Akhtar ${ }^{\mathrm{a}}$, Sabir Khan ${ }^{\mathrm{b}}$, Salma Kadar ${ }^{\mathrm{c}}$

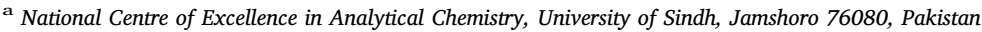 \\ b Universidade Estadual Paulista (UNESP), Department of Analytical Chemistry, Institute of Chemistry, Rua Professor Francisco Degni, 55, Quitandinha, 14.800-060 \\ Araraquara, Brazil \\ ${ }^{c}$ Neuro Diagnostic Centre, Liaquat University of Medical \& Health Sciences, Jamshoro, Pakistan
}

\section{A R T I C L E I N F O}

\section{Keywords:}

Calcium

Copper

Iron

Serum

Bile

Different types of gallstone

\begin{abstract}
A B S T R A C T
Background: Epidemiological data among the human population has shown a significantly increased incidence of gallstone (GS) disease worldwide. It was studied that some essential (calcium) and transition elements (iron and copper) in bile play an important role in the development of GS.

Method: The estimation of calcium, copper and iron were carried out in the serum, gall bladder bile and different types of GS (cholesterol, mixed and pigmented) of 172 patients, age ranged 20-55 years. For comparative purpose age matched referents not suffering from GS diseases were also selected. Biliary concentrations of calcium $(\mathrm{Ca})$, iron $(\mathrm{Fe})$ and copper $(\mathrm{Cu})$ were correlated with their concentrations in serum and different types of GS samples. The ratio of $\mathrm{Ca}, \mathrm{Fe}$ and $\mathrm{Cu}$ in bile with serum was also calculated. Understudy metals were determined by flame atomic absorption spectroscopy after acid decomposition of matrices of selected samples. Results: The Ca concentrations in serum samples were significantly higher in patients with pigmented GS as compared to controls ( $\mathrm{p}<0.005$ ), whereas for patients having cholesterol and mixed GS the concentrations were on the lower side. Biliary $\mathrm{Ca}$ concentrations of patients were found to be higher than controls, but difference was significant for pigmented GS patients ( $\mathrm{p}>0.001$ ). The contents of $\mathrm{Cu}$ and Fe in serum and bile of all patients (except female cholesterol GS patient have low serum iron concentration) were found to be higher than control, but difference was significant in those patients who have pigmented GS. The concentration of Ca, $\mathrm{Fe}$ and $\mathrm{Cu}$ in different types GS were found in the order, Pigmented $>$ mixed $>$ cholesterol. The bile/serum ratio for $\mathrm{Ca}, \mathrm{Cu}$ and $\mathrm{Fe}$ was found to be significantly higher in pigmented GS patients. Gall bladder bile was slightly alkaline in patients as compared to referents. The density of bile was found to be higher in patients as compared to the referents. Various functional groups present in different types of GS samples were confirmed by Fourier transform infra-red spectroscopy.

Conclusion: The higher density and $\mathrm{pH}$ of bile, elevated concentrations of transition elements in all types of biological samples (serum, bile and GS), could be an important factor for the formation of different types of GS.
\end{abstract}

\section{Introduction}

GS formation is considered to be one of the most common diseases of digestive system. GS stone pathogenesis mystery is not keenly defined but some of the spectroscopic and chemical studies have revealed some clues regarding its materialization. Metals are believed to be involved in the concretion of bile in gall bladder [1]. GS have 3 kinds on the basis of their major chemical composition i.e. Cholesterol, mixed and pigmented GS (Fig. 1). Cholesterol GS contain cholesterol as their main constituent, pigmented gall stone have higher amount of bilirubin and bilirubinate while mixed GS are combination of the other two. Super saturation of bile with cholesterol is responsible for the development of cholesterol GS while pigmented GS are mostly formed in physiological condition like hemolytic anemia and infected bile [2]. The contributing factors for the materialization of GS include, changes in the constituents of hepatic bile, infection, genetic factors, biliary glycoprotein, age, sex, estrogen, geographical dominancy and liver cirrhosis [2]. In the absence of medical conditions such as hemolytic anemia and infected bile, the genesis of pigmented and mixed GS remains unclear [3]. The main investigated constituents in human

\footnotetext{
* Corresponding author.

E-mail address: mustafakhan2313@yahoo.com (M. Khan).
} 


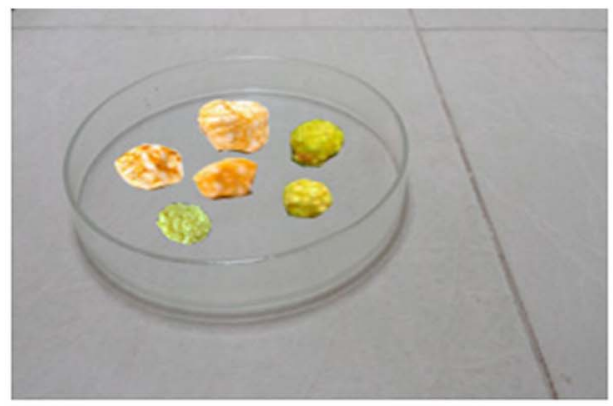

Fig. 1. Images of different types of gallstones.

\section{Cholesterol gallstone}
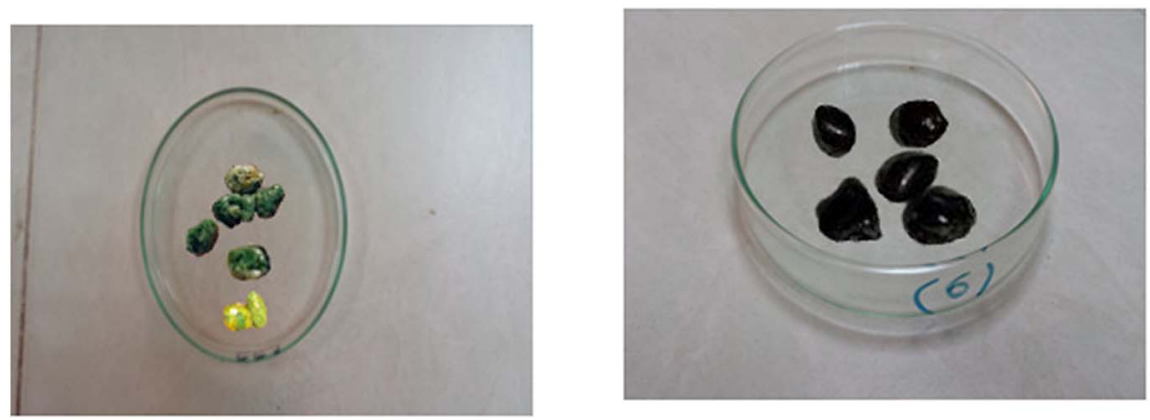

\section{Mixed gallstone}

\section{Pigmented gallstone}

gallstone are bilirubin, bilirubinate salts and cholesterol. Beside these many other compounds like, various cholic acid derivatives, fatty salts, calcium carbonate, calcium bilirubinate, calcium phosphate salts, proteins and polysaccharide have been found in human gallstone [4,5]. In order to maintain the trace elements balance in the body, the elements which are existing as positively charged cations and those existing as negatively charged anions are mainly absorbed from gastrointestinal tract while their excretion usually occur through, bile, sweat, urine and breath [4]. Elements like $\mathrm{Fe}$ and $\mathrm{Cu}$ are eliminated from the liver via bile. Variation in the composition of bile encourages its immobilization and concretion of in the gallbladder [6]. The role of minor and trace element concentration in gallstone disease and other health disorders is of prime importance in the field of medicine from very long time [7]. Moreover certain disease in the human body is related to the varying concentrations of these trace elements in the body.

\section{Materials and methods}

\subsection{Chemicals and reagents}

Ultrapure water prepared by ELGA Lab Water system ELGA was used throughout the experimental work. All acids and other chemicals were of analytical grad supplied by Merck. Certified reference material for serum (Clincheck control-lyophilized ${ }^{\circledR}$ serum). Certified standard solutions $(1000 \mu \mathrm{g} / \mathrm{ml}$; Fluka kamika) of $\mathrm{Ca}, \mathrm{Cu}$ and Fe were diluted to make working solutions before analysis.

\subsection{Apparatus}

Microwave digestion of all the samples were carried out by a Pel (PMO23) domestic microwave oven (maximum heating power of 900 W). A Perkin Elmer. An Analyst 700 atomic absorption spectrometer with (deuterium background corrector and laminar flame burner) was used for the determination of the elements. A hollow cathode lamp (single element) was put to work at 7.5, 7.5 and $7.0 \mathrm{~mA}$ with wavelength 422.7, 248.5 and $324.8 \mathrm{~nm}$ for $\mathrm{Ca}$, $\mathrm{Fe}$ and $\mathrm{Cu}$ respectively. A flow rate of $17.0 \mathrm{l} / \mathrm{min}$ for air (oxidant) and $2.01 / \mathrm{min}$ for acetylene were maintained. Manufacturer's specifications were instantly followed for the maintenance of other instrumental conditions. Preparation and storage of reagent and standard solutions were carried out in Acidwashed polytetrafluoroethylene (PTFE) vessels and flasks. Infrared spectra measurements of each type of gallstones were carried out by a Thermo Nicolet 5700 FTIR spectrometer (Thermo Nicolet Analytical Instruments). The FTIR equipped with $\mathrm{KBr}$ optics and deuterated triglycine sulfate detector and the working conditions were managed by a software package OMNIC. The spectra were performed on grounded solid samples as $\mathrm{KBr}$ pellets.

\subsection{Studied population}

The study included $(n=172)$ patients having different types of GS, of age group 20-55 years. Only those patients were selected for the study, whose bile, stones and serum samples were collected. Patients without their bile or stones collection and those who were on iron or calcium supplements were excluded from the study. For comparative purpose the bile $(n=25)$ and serum $(n=68)$ samples in age and sex matched controls referents were also collected. Prior to the start of study, a questionnaire was developed from all patients and control referents in order to gather information about their physical data, racial origin, nutritional routines, age, and consent. The demographical data of gallstone patients was described in Table 1 .

\subsection{Biological sampling and pre-treatment}

Before starting this study, an approval was obtained from the ethical review committee of University of Sindh, Jamshoro and Mardan Medical Complex and Teaching Hospital Mardan, Pakistan. All patients and control referents were provided with a written consent before the collection of their samples, confirming that they were willing for giving their blood, bile and GS samples and they were informed about the whole experimental procedure. The GS samples were collected randomly from patients of both genders, after their cholecystectomy. All 
Table 1

Demographics of different types of gallstone patients and control referents age group (20-55 years).

\begin{tabular}{|c|c|c|c|c|c|c|c|c|}
\hline \multicolumn{4}{|l|}{ Male } & \multicolumn{4}{|l|}{ Female } & \multirow{3}{*}{$\begin{array}{l}\text { Clinical history of GS patients } \\
\text { Intense pain in upper right portion of abdomen } \\
\text { High fever with chills }\end{array}$} \\
\hline \multirow[t]{2}{*}{ Referent serum/bile ${ }^{\mathrm{b}}$} & \multicolumn{3}{|c|}{ Patients (serum/bile/stones) } & \multirow[t]{2}{*}{ Referent serum/bile } & \multicolumn{3}{|c|}{ Patients (serum/bile/stones) } & \\
\hline & Cholesterol $^{\mathrm{a}}$ & Pigment & Mixed & & Cholesterol & Pigment & Mixed & \\
\hline $33 / 11$ & 40 & 8 & 12 & $35 / 14$ & 80 & 12 & 20 & $\begin{array}{l}\text { Back pain between shoulder blades } \\
\text { Vomiting or nausea }\end{array}$ \\
\hline
\end{tabular}

${ }^{\text {a }}$ Different types of gallstones.

${ }^{\mathrm{b}}$ Serum and bile samples from control referent of the same age group.

recovered stones were washed with ultra-pure water and rinsed with acetone, and then made air-dried in a dark room for several days to avoid photodecompositions of bilirubin. All dried samples were crushed into fine powder and stored in clean polyethylene bags. The gallstones appeared from amorphous yellow to crystalline black in color.

Bile samples (6 to $10 \mathrm{~mm}$ ) were collected from gall bladder of patients/controls using a 23-gauge needle with the help of aspiration technique. Twenty of the control patients had an exploratory laparotomy and the remaining five patients underwent elective surgery. All the patients and control subjects were recovered without any complication. The $\mathrm{pH}$ and density of the bile were determined without any delay of time. After the $\mathrm{pH}$ and density determination $5 \mathrm{ml}$ analytical grade ethanol were added to the bile and stored in sterilized specimen bottles in a refrigerator until further analysis.

The venous blood samples $(5 \mathrm{ml})$ from patients and controls were collected before the induction of anesthesia, using metal free safety heparinized Vacutainer ${ }^{\circledast}$ blood collecting tubes (Becton Dickinson, Rutherford $^{\circledR}$, USA). The blood samples were made to clot at room temperature for 15-30 min. After the complete clotting, centrifuged at $2500 \mathrm{rpm}$ for 5-10 min. The supernatant fluid (serum) was separated with the help of Pasteur pipette and labeled accordingly. It was stored at $-20{ }^{\circ} \mathrm{C}$ until further analysis.

\subsection{Density and $p H$ of bile samples}

$\mathrm{pH}$ of the gall bladder bile of both referent subjects and GS patients having different types of stones i.e. cholesterol, pigmented and mixed were determined with the help of calibrated microelectrode $\mathrm{pH}$ meter. Density of the gall bladder bile of both referent subjects and GS patients having different types of stones i.e. cholesterol, pigmented and mixed were determined with the help of calibrated specific gravity bottles having a capacity of $10 \mathrm{ml}$.

\subsection{Microwave-assisted acid digestion}

Duplicate samples of each gallstone sample $(0.5 \mathrm{~g})$, serum $(0.5 \mathrm{ml})$ and bile $(0.5 \mathrm{ml})$ were weighed in PTFE flasks. $2 \mathrm{ml}$ of concentrated $\mathrm{HNO}_{3}$ and $\mathrm{H}_{2} \mathrm{O}_{2}$ in ratio of $2: 1(\mathrm{v} / \mathrm{v})$ were added. The flasks were kept at room temperature for $10 \mathrm{~min}$. The contents were then subjected to microwave heating for 5 to $10 \mathrm{~min}$, detail procedure is reported in previous work $[8,9]$. The clear solution after digestion was made up to $10 \mathrm{ml}$ in volumetric flask with $0.2 \mathrm{~N} \mathrm{HNO}_{3}$. Blanks were also prepared simultaneously. The validity and accuracy of methodology was checked by spiking standards in real samples at 3 concentrations (Table 4).

\subsection{Statistical analysis}

All statistical analyses were performed using the computer program Excel (Microsoft Corp.) and Minitab 13.2 (Minitab Inc). The correlation and significant difference of understudy elements among various biological samples of patients with different types of GS, were studied by Spearman correlation analysis and nonparametric Mann-Whitney $U$ tests.

\subsection{Analytical figures}

The calibration plots were drawn after analyzing standard solutions of $\mathrm{Ca}, \mathrm{Cu}$ and $\mathrm{Fe}$. The concentration range for $\mathrm{Ca}$ was $0.5-2 \mathrm{mg} / \mathrm{l}$, whereas for $\mathrm{Fe}$ and $\mathrm{Cu}$ the concentration was ranging from quantification limit up to $0.35-1.35$ and $0.45-1.34 \mathrm{mg} / \mathrm{l}$. For each element linear graphs, with correlation coefficient in the range of 0.9997-0.998, were obtained. The limits of detection (LOD) were 164.3, 69.2 and $17.3 \mu \mathrm{g} / \mathrm{l}$ for $\mathrm{Ca}, \mathrm{Fe}$ and $\mathrm{Cu}$, respectively. The accuracy of the method was verified by spiking standard solutions of understudy elements at three concentration concentrations. The precision of the method was checked by finding out percent relative \%RSD, after 6 replicate analysis of $10 \mu \mathrm{g} / 1$ standard of the metals (Table 5 ).

\section{Results}

\subsection{FTIR analysis}

FTIR spectroscopy was carried out to confirm the classification of GS which we have made with the help of visual aid [10]. The type of stone, the main chemical constituent of each type and its corresponding absorbing IR bands obtained along with literature values [5,11-17] are given in (Table 6). Representative infrared spectra of cholesterol, pigmented and mixed gallstones are shown in Figs. 2-4, respectively.

\subsection{Serum analysis}

The mean concentration of $\mathrm{Ca}, \mathrm{Fe}$ and $\mathrm{Cu}$ along with SD in serum samples of both male and female referents subjects and GS patients are given in the Table 7. The contents of $\mathrm{Ca}$ in serum samples of male referent subjects and GS patients having different types of stones i.e. (cholesterol, pigmented, mixed) of age group 20-55 years were found at $95 \% \mathrm{Cl}: 74.2-77.1 \mathrm{mg} / \mathrm{l}$ and $\mathrm{Cl}:$ 68.7-71, Cl: 91.4-94.1, Cl: 70.1-72.4 mg/1 respectively. While in case of female referents subjects and GS patients (cholesterol, pigmented, mixed) have serum Ca concentrations $\mathrm{Cl}$ : $78-81 \mathrm{mg} / \mathrm{l}$ and $\mathrm{Cl}$ : 71.5-73.1, Cl: 89.1-91.4, Cl: $72.3-74 \mathrm{mg} / \mathrm{l}$, respectively. The range of Fe concentration in serum samples of male and female referent subjects were found at $95 \% \mathrm{CI}$ : 1.51-1.71 and $\mathrm{Cl}: 1.41-1.52 \mathrm{mg} / \mathrm{l}$ respectively. While serum Fe contents in male and female GS patient's with different types of stones i.e. cholesterol, pigmented, mixed were found at 95\% CI: $1.46-1.58, \mathrm{Cl}$ : 1.63-1.85, Cl: $1.48-1.59$ and $\mathrm{Cl}: 1.38-1.46, \mathrm{Cl}: 1.58-1.72$, and $\mathrm{Cl}$ : $1.44-1.53 \mathrm{mg} / \mathrm{l}$ respectively. The concentration of $\mathrm{Cu}$ in serum samples of male and female referents were found at $95 \% \mathrm{Cl}$ : 1.53-1.65 and $\mathrm{Cl}$ : $1.36-1.47 \mathrm{mg} / \mathrm{l}$ respectively. While in case of patients both male and female having GS of different origin i.e. cholesterol, pigmented, mixed, serum $\mathrm{Cu}$ were found at $95 \% \mathrm{CI}$ : $1.56-1.67, \mathrm{Cl}: 2.14-2.32, \mathrm{Cl}$ : 1.61-1.74 and $\mathrm{Cl}: 1.42-1.51, \mathrm{Cl}: 1.87-1.98, \mathrm{Cl}: 1.46-1.56 \mathrm{mg} / \mathrm{l}$ respectively. The correlation ( $\mathrm{r}$ ) between $\mathrm{Ca}$ and $\mathrm{Fe}$ were found to be highly significant in serum samples of pigmented GS patients, while it was moderately correlated in cholesterol and mixed GS patients. A moderate correlation between $\mathrm{Ca}$ and $\mathrm{Cu}$ in the serum samples were found for all types of gallstone patients (Table 8). 

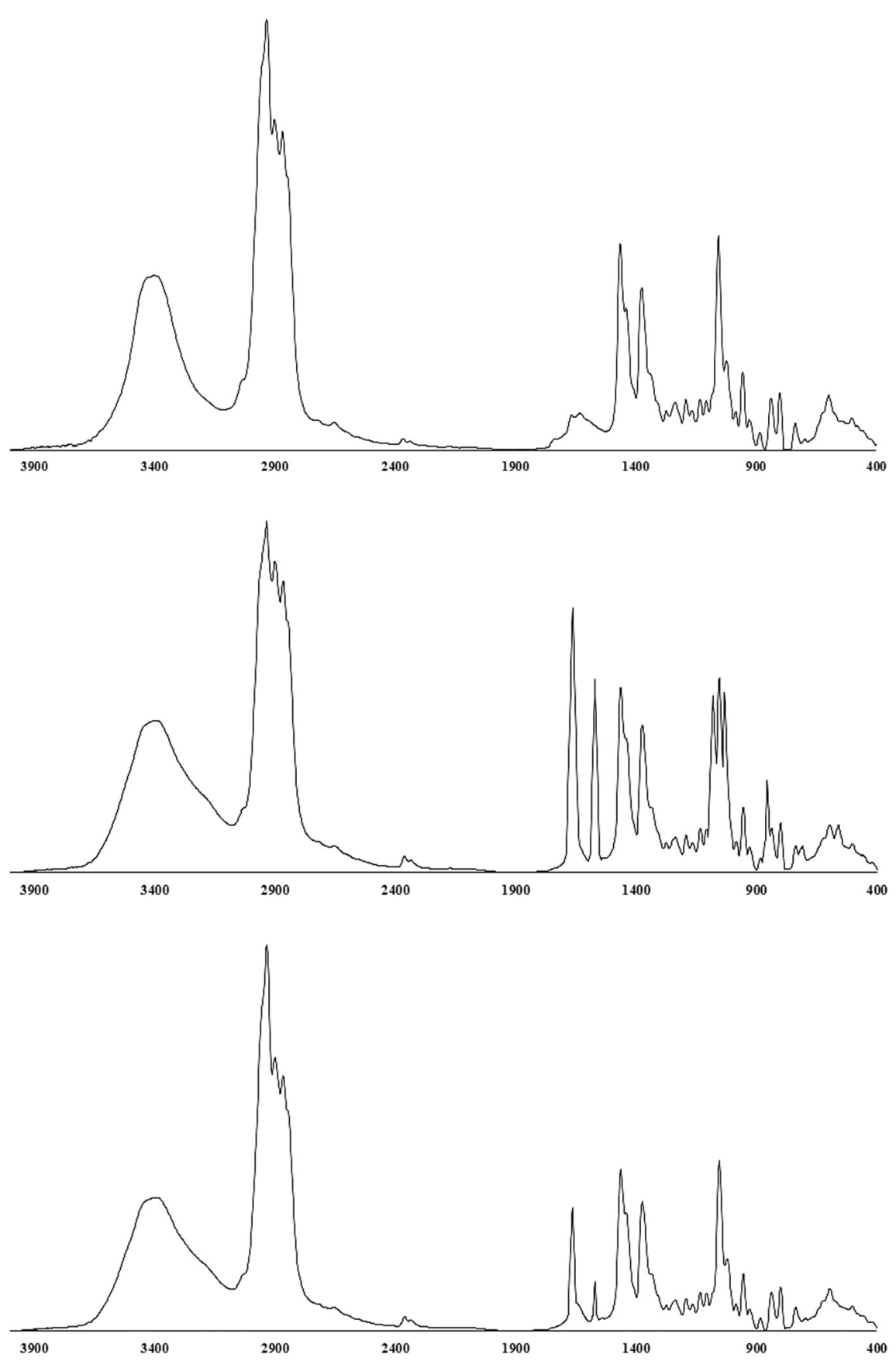

Fig. 2. Infrared spectra of cholesterol gallstone samples.

Fig. 3. Infrared spectra of pigmented gallstone samples.

Fig. 4. Infrared spectra of mixed gallstone samples.

Table 2

$\mathrm{pH}$ and density comparison of bile in referents and patients having different types of gallstone.

\begin{tabular}{|c|c|c|c|c|c|}
\hline Parameters & Gender & Referents & Cholesterol & Pigmented & Mixed \\
\hline \multirow[t]{2}{*}{$\mathrm{pH}$} & Male & $6.71 \pm 0.03$ & $7.13 \pm 0.05$ & $7.47 \pm 0.03$ & $7.15 \pm 0.04$ \\
\hline & Female & $6.72 \pm 0.02$ & $7.11 \pm 0.03$ & $7.45 \pm 0.04$ & $7.12 \pm 0.05$ \\
\hline \multirow[t]{2}{*}{ Density $(\mathrm{g} / \mathrm{ml})$} & Male & $1.17 \pm 0.002$ & $1.38 \pm 0.003$ & $1.62 \pm 0.002$ & $1.45 \pm 0.004$ \\
\hline & Female & $1.15 \pm 0.003$ & $1.36 \pm 0.004$ & $1.63 \pm 0.003$ & $1.42 \pm 0.002$ \\
\hline
\end{tabular}

\subsection{Bile analysis}

The bile $\mathrm{pH}$ for referents subjects, cholesterol, pigmented and mixed GS patients were found at 95\% Cl: $6.70-6.73, \mathrm{Cl}: 7.12-7.15, \mathrm{Cl}$ : 7.45-7.50 and $\mathrm{Cl}: 7.13,7.17$, respectively (Table 2). There was no significant difference in the bile $\mathrm{pH}$ for male and female subjects. Gall bladder bile density for referent subjects, cholesterol, pigmented and mixed stone patients were found at $95 \% \mathrm{Cl}$ : 1.16-1.17, Cl: 1.37-1.38, Cl: 1.61-1.62 and Cl: 1.44-1.45 respectively (Table 2).

The mean concentration of $\mathrm{Ca}$, Fe and $\mathrm{Cu}$ along with standard deviation in bile samples of both male and female referents subjects and GS patients are given in the Table 7. The contents of Ca in bile samples of male referent subjects and GS patients having different types of stones i.e. (cholesterol, pigmented, mixed) were found at $95 \% \mathrm{Cl}$ : 
Table 3

$\mathrm{Bile} /$ serum ratio for $\mathrm{Ca}, \mathrm{Fe}$ and $\mathrm{Cu}$ in referents and gallstone patients.

\begin{tabular}{llllll}
\hline \multirow{2}{*}{ Metals } & \multirow{2}{*}{ Gender } & \multicolumn{3}{l}{ Bile/serum ratio (\%) } \\
\cline { 3 - 6 } & & Referents $^{\mathrm{a}}$ & Cholesterol $^{\mathrm{b}}$ & Pigment & Mixed \\
\hline \multirow{2}{*}{$\mathrm{Ca} \mathrm{(mg/l)}$} & Male & 92 & 105 & 104 & 104 \\
& Female & 91 & 103 & 108 & 101 \\
$\mathrm{Fe}(\mathrm{mg} / \mathrm{l})$ & Male & 83 & 86 & 114 & 87 \\
& Female & 78 & 85 & 110 & 84.4 \\
$\mathrm{Cu}(\mathrm{mg} / \mathrm{l})$ & Male & 85.5 & 108 & 130 & 109 \\
& Female & 83 & 105 & 110 & 107 \\
\hline
\end{tabular}

a Different types of gallstones.

${ }^{\mathrm{b}}$ Serum and bile samples from control referent of the same age group.

\section{Table 4}

Determination of $\mathrm{Ca}, \mathrm{Fe}$ and $\mathrm{Cu}$ in certified reference material of serum (Clincheck control-lyophilized ${ }^{\circledR}$ serum) $(\mathrm{mg} / \mathrm{l})$ by the proposed method and standard addition to the real samples of bile and gallstone $(n=6){ }^{\text {a }}$

\begin{tabular}{lllll}
\hline Metals & Certified value & Obtained value & $\begin{array}{l}\text { Paired } t \text {-test } \\
\text { tvalue }\end{array}$ & \% recovery \\
\hline $\mathrm{Ca}$ & $58.0 \pm 1.90^{\mathrm{a}}$ & $57.4 \pm 0.560$ & 0.707 & 99.0 \\
$\mathrm{Fe}$ & $1.964 \pm 0.300$ & $1.959 \pm 0.109$ & 0.311 & 99.4 \\
$\mathrm{Cu}$ & $1.562 \pm 0.56$ & $1.556 \pm 0.120$ & 0.434 & 99.3 \\
& & & & \\
\hline
\end{tabular}

Standard addition to real samples of bile and gallstone

\begin{tabular}{|c|c|c|c|c|c|}
\hline \multirow[t]{2}{*}{ Metals } & \multirow{2}{*}{$\begin{array}{l}\text { Added (ppm) } \\
\text { Bile/GS }\end{array}$} & \multicolumn{2}{|c|}{ Found } & \multicolumn{2}{|c|}{$\%$ recovery } \\
\hline & & Bile & GS & Bile & GS \\
\hline \multirow[t]{4}{*}{$\mathrm{Ca}$} & 0 & 20.5 & 25.2 & - & - \\
\hline & 5 & 25.1 & 30.2 & 98 & 97 \\
\hline & 10 & 29.5 & 35.2 & 97 & 98 \\
\hline & 15 & 34.2 & 39.8 & 96 & 99 \\
\hline \multirow[t]{4}{*}{$\mathrm{Fe}$} & 0 & 10.1 & 15.2 & - & - \\
\hline & 5 & 14.8 & 19.2 & 98 & 95 \\
\hline & 10 & 19.8 & 24.6 & 99 & 98 \\
\hline & 15 & 24.5 & 29.3 & 98 & 97 \\
\hline \multirow[t]{4}{*}{$\mathrm{Cu}$} & 0 & 10.5 & 10.8 & - & - \\
\hline & 5 & 15.3 & 15.2 & 98 & 96 \\
\hline & 10 & 20.4 & 20.3 & 99 & 97 \\
\hline & 15 & 25.1 & 24.9 & 98 & 98 \\
\hline
\end{tabular}

${ }^{a}$ Paired $t$-test between certified values vs found values, degree of freedom $(\mathrm{n}-1)$

$=5$, $\mathrm{T}$ (critical) at $95 \% \mathrm{CI}=2.570$.

${ }^{\mathrm{b}}$ Mean $\pm \mathrm{SD}$

Table 5

Analytical features of the method.

\begin{tabular}{llllll}
\hline Metal & Concentration range, mg/1 & $\mathrm{R}^{2}$ & $\begin{array}{c}\% \mathrm{CV}^{\mathrm{a}} \\
\mathrm{n}=6\end{array}$ & $\mathrm{LOD}^{\mathrm{b}}, \mu \mathrm{g} / \mathrm{l}$ & $\mathrm{LOQ}^{\mathrm{c}}, \mathrm{mg} / 1$ \\
\hline $\mathrm{Ca}$ & $2-50$ & 0.999 & 3.01 & 164.3 & 0.52 \\
$\mathrm{Fe}$ & $2-50$ & 0.999 & 4.12 & 69.2 & 0.34 \\
$\mathrm{Cu}$ & $2-50$ & 0.998 & 3.51 & 17.3 & 0.42 \\
\hline
\end{tabular}

a $\% \mathrm{CV}(10 \mathrm{mg} / \mathrm{l})$.

${ }^{\mathrm{b}}$ Limit of Detection. Calculated as three times the ratio between standard deviation of 10 blank signals and slop of the calibration graph $(3 \sigma / \mathrm{m})$.

${ }^{\mathrm{c}}$ Limit of Quantification. Calculated as ten times the ratio between standard deviation of 10 blank signals and slop of the calibration graph $(10 \sigma / \mathrm{m})$.

67.4-71.6 mg/1 and $\mathrm{Cl}$ : 72.3-74.6, $\mathrm{Cl}:$ 80.5-82.7, and $\mathrm{Cl}$ : $72.8-75.4 \mathrm{mg} / \mathrm{l}$ respectively, same trend of resulted data were observed in female control and patients. The range of Fe concentration in bile samples of male and female referent subjects were found at $95 \% \mathrm{Cl}$ : 1.17-1.38 and $\mathrm{Cl}: 1.06-1.23 \mathrm{mg} / \mathrm{l}$ respectively. While bile Fe contents in male and female GS patients with different types of stones i.e. cholesterol, pigmented, mixed were found at $95 \% \mathrm{Cl}$ : 1.27-1.36, Cl: 1.90, 2.05, Cl: 1.27-1.41 and Cl: 1.18-1.24, Cl: 1.77-1.87, and Cl: 1.21-1.29, $\mathrm{mg} / \mathrm{l}$ respectively. The concentration of $\mathrm{Cu}$ in bile samples of male and female referents were found at $95 \% \mathrm{Cl}: 1.22-1.49$ and $\mathrm{Cl}$ : $1.06-1.29 \mathrm{mg} / 1$ respectively. While in case of patients both male and female having GS of different origin i.e. cholesterol, pigmented, mixed, bile $\mathrm{Cu}$ were found at $95 \% \mathrm{Cl}: 1.66-1.84, \mathrm{Cl}: 2.77-3.00$, Cl: 1.73-1.91, and $\mathrm{Cl}: 1.49-1.59, \mathrm{Cl}: 2.06-2.20$, and $\mathrm{Cl}: 1.56-1.66 \mathrm{mg} / \mathrm{l}$ respectively. The correlation ( $r$ ) between $\mathrm{Ca}$ and $\mathrm{Fe}$ in bile samples of pigmented GS patients was found to be significant. While in case of cholesterol and mixed GS patients the concentration of $\mathrm{Ca}$ and Fe were moderately correlated in bile samples. A highly significant correlation were found between the concentration of $\mathrm{Ca}$ and $\mathrm{Fe}$ in bile samples of pigmented and mixed GS patients as compared to that of cholesterol GS patients as shown in the Table 8.

\subsection{Gallstone analysis}

The mean concentration of $\mathrm{Ca}, \mathrm{Fe}$ and $\mathrm{Cu}$ along with standard deviation in serum samples of both male and female referents subjects and GS patients are given in the Table 7. The content of $\mathrm{Ca}$ in male and female of age group 20-55 years having different types of GS, cholesterol, pigmented and mixed were found at 95\% Cl: 1340-1525, Cl: 43,100-45,900, Cl: $14,600-16,200$ and $\mathrm{Cl}$ : 1520-1660, Cl: $45,400-48,100$, and $\mathrm{Cl}: 16,000-17,400 \mu \mathrm{g} / \mathrm{g}$ respectively. While the concentration of iron in male and female GS samples were found at $95 \%$ Cl: 21.8-23.1, Cl: 1030-1100, Cl: $102-110$ and $\mathrm{Cl}: 21.2-22.4, \mathrm{Cl}$ : 1030-1150, Cl: $100-110 \mu \mathrm{g} / \mathrm{g}$ respectively. The concentration of $\mathrm{Cu}$ in GS samples of both male and female were found at $95 \% \mathrm{Cl}$ : $630-660$, Cl: 1940-2070, Cl: 1270-1350 and Cl: 590-620, Cl: 1870-2040, Cl: $1010-1130 \mu \mathrm{g} / \mathrm{g}$ respectively. The correlation between Ca and Fe were found to be significant in GS samples of pigmented GS patients, while an insignificant and moderate correlation were found for cholesterol and mixed GS patients respectively. The correlation between $\mathrm{Ca}$ and $\mathrm{Fe}$ in GS samples was found to be highly significant in pigmented and mixed GS patients as compared to that of cholesterol GS patients (Table 8).

The concentrations of the understudy metals were correlated in various biological samples of GS patients having different types (cholesterol, pigmented and mixed). The concentration of Ca was found to be significantly correlated between serum and bile, bile and stone samples of pigmented GS patients $(r=0.66),(r=0.51)$ respectively, while it was moderately correlated between other biological samples of the pigmented GS patients as well as in the mixed and cholesterol GS patients as shown in the Table 8. The contents of iron were found to be significantly correlated between serum and bile, bile and stone samples of pigmented GS patients $(r=0.65),(r=0.44)$ respectively. Whereas it was moderately correlated between other biological samples of the pigmented GS patients as well as in the mixed and cholesterol GS patients as shown in the Table 8. The correlation of $\mathrm{Cu}$ follow similar trend as that was observed for Fe as shown in the Table 8.

\subsection{Bile/serum ratio}

Bile/serum ratio for $\mathrm{Ca}, \mathrm{Fe}$ and $\mathrm{Cu}$ in in different types of GS patients for both genders were compared with the referent subjects. The ratio was found to be higher in gallstone patients as compared to referents. However, bile/serum ratio was significantly higher in pigmented gallstone patients than cholesterol and mixed gallstone patients, as shown in Table 3.

\section{Discussion}

\subsection{FTIR analysis}

The stronger absorbing bands in the region between 3000 and $2800 / \mathrm{cm}$ as shown in the Fig. 2, are due to symmetric and asymmetric stretching vibration of $-\mathrm{CH}_{3}$ and $-\mathrm{CH}_{2}$ groups $[5,15]$. The broad and 
Table 6

IR bands of main components observed in different types of gallstones compared with literature values.

\begin{tabular}{|c|c|c|c|c|c|}
\hline S. no & Gallstone color & Classification & Main components & IR bands observed & Literature value $[5,11-17]$ \\
\hline 1 & White or yellowish white & Cholesterol & Cholesterol & $2933.9,2867.9,1465,1375.4,1056$ & $\begin{array}{l}2925 \mathrm{CH}_{2} \text { and } \mathrm{CH}_{3} \text { asymmetric stretching } \\
2860 \mathrm{CH}_{2} \text { and } \mathrm{CH}_{3} \text { asymmetric stretching } \\
1460,1380 \mathrm{CH}_{2} \text { and } \mathrm{CH}_{3} \text { bending } \\
1050 \mathrm{C}-\mathrm{C} \text { stretching }\end{array}$ \\
\hline \multirow[t]{3}{*}{2} & Black & Pigmented & Bilirubin & $1664,1627,1571.7$ & $\begin{array}{l}1670,1640 \mathrm{OC}=\mathrm{O} \text { stretching } \\
1575 \mathrm{C}=\mathrm{C} \text { stretching }\end{array}$ \\
\hline & & & Calcium carbonate & $1082,873.6,856,711$ & $\begin{array}{l}1082 \mathrm{O}-\mathrm{C} \text { stretching } \\
875 \mathrm{C}-\mathrm{O} \text { bending } \\
856 \mathrm{CO}_{3}{ }^{2-} \text { out-of-plane deformation } \\
713 \mathrm{OCO}^{-} \text {bending }\end{array}$ \\
\hline & & & Calcium phosphate & $1033,598.3,561.2$ & $\begin{array}{l}1036 \text { stretching vibrations of } \mathrm{PO}_{3}-{ }^{4} \text { group } \\
603,562\end{array}$ \\
\hline 3 & Brownish yellow or greenish & Mixed & Cholesterol and bilirubin & 2933.9, 2867.9, 1664, 1575, 1465, 1375.4, 1056 & Same as above \\
\hline
\end{tabular}

Table 7

$\mathrm{Ca}, \mathrm{Fe}$ and $\mathrm{Cu}$ contents in selected samples of Male and female referents and gall stones patients (age group 20-55 years).

\begin{tabular}{|c|c|c|c|c|c|}
\hline Metals & Gender & Referents $^{\mathrm{a}}$ & Cholesterol $^{\mathrm{b}}$ & Pigment & Mixed \\
\hline \multicolumn{6}{|c|}{ Serum (mg/l) } \\
\hline \multirow[t]{2}{*}{$\mathrm{Ca}$} & Male & $75.6 \pm 4.25$ & $69.8 \pm 3.65$ & $92.7 \pm 4.12$ & $71.2 \pm 3.83$ \\
\hline & Female & $79.3 \pm 5.13$ & $72.3 \pm 3.43$ & $90.2 \pm 5.43$ & $73.1 \pm 3.90$ \\
\hline \multirow[t]{2}{*}{$\mathrm{Fe}$} & Male & $1.53 \pm 0.22$ & $1.52 \pm 0.19$ & $1.74 \pm 0.37$ & $1.54 \pm 0.18$ \\
\hline & Female & $1.46 \pm 0.16$ & $1.42 \pm 0.17$ & $1.65 \pm 0.29$ & $1.48 \pm 0.21$ \\
\hline \multirow[t]{2}{*}{$\mathrm{Cu}$} & Male & $1.59 \pm 0.19$ & $1.62 \pm 0.18$ & $2.23 \pm 0.29$ & $1.67 \pm 0.22$ \\
\hline & Female & $1.42 \pm 0.17$ & $1.46 \pm 0.19$ & $1.93 \pm 0.24$ & $1.51 \pm 0.21$ \\
\hline \multicolumn{6}{|c|}{ Bile (mg/l) } \\
\hline \multirow[t]{2}{*}{$\mathrm{Ca}$} & Male & $69.5 \pm 3.75$ & $73.4 \pm 3.81$ & $81.6 \pm 3.65$ & $74.1 \pm 3.98$ \\
\hline & Female & $72.3 \pm 4.12$ & $74.3 \pm 3.64$ & $83.4 \pm 3.85$ & $73.8 \pm 3.25$ \\
\hline \multirow[t]{2}{*}{$\mathrm{Fe}$} & Male & $1.27 \pm 0.18$ & $1.32 \pm 0.15$ & $1.98 \pm 0.25$ & $1.34 \pm 0.22$ \\
\hline & Female & $1.14 \pm 0.16$ & $1.21 \pm 0.14$ & $1.82 \pm 0.21$ & $1.25 \pm 0.20$ \\
\hline \multirow[t]{2}{*}{$\mathrm{Cu}$} & Male & $1.36 \pm 0.24$ & $1.75 \pm 0.29$ & $2.89 \pm 0.36$ & $1.82 \pm 0.28$ \\
\hline & Female & $1.18 \pm 0.22$ & $1.54 \pm 0.25$ & $2.13 \pm 0.34$ & $1.61 \pm 0.25$ \\
\hline \multicolumn{6}{|c|}{ Gallstone $(\mu \mathrm{g} / \mathrm{g})$} \\
\hline \multirow[t]{2}{*}{$\mathrm{Ca}$} & Male & - & $1435 \pm 295$ & $44,530 \pm 1965$ & $15,405 \pm 1315$ \\
\hline & Female & $\bar{\square}$ & $1590 \pm 310$ & $46,750 \pm 2390$ & $16,700 \pm 1580$ \\
\hline \multirow[t]{2}{*}{$\mathrm{Fe}$} & Male & {[} & $22.45 \pm 2.24$ & $1087.5 \pm 81$ & $106.3 \pm 7.23$ \\
\hline & Female & & $21.8 \pm 2.73$ & $1069 \pm 64.85$ & $103.85 \pm 9.03$ \\
\hline \multirow[t]{2}{*}{$\mathrm{Cu}$} & Male & $\bar{\square}$ & $646 \pm 51$ & $2005 \pm 101$ & $1315 \pm 67.7$ \\
\hline & Female & $\bar{L}$ & $612 \pm 56.5$ & $1957.5 \pm 151$ & $1104.5 \pm 70.7$ \\
\hline
\end{tabular}

${ }^{\text {a }}$ Serum sample of healthy subjects of same age group.

b Different types of gallstones.

intense band at $3400 / \mathrm{cm}$ is assigned to the stretching vibration of $-\mathrm{OH}$ group present in the cholesterol $[15,17]$ The bands appeared at 2933.9, 2867.9, 1465, 1375.4 and 1056.4 are the major and strong bands indicating the presence of cholesterol in the GS samples of cholesterol in origin $[13,14]$. In the FTIR spectrum of pigmented GS the absorbance bands in the region between 1700 and $1500 / \mathrm{cm}$ are due to the stretching vibration of $\mathrm{C}=\mathrm{C}, \mathrm{CO}$, and $\mathrm{C}-\mathrm{N}$ at $1571.7,1627$ and at $1664.3 / \mathrm{cm}$ due to bilirubin and bilirubinate salts $[14,16]$. The broad band around $3400 / \mathrm{cm}$ arises due to stretching vibrations of $-\mathrm{OH}$ and $-\mathrm{NH}$ in cholesterol and bilirubin pyrrole respectively. The absorbance bands that mostly appeared at 1081, 856 and $712 / \mathrm{cm}$ are due to $\mathrm{CaCO}_{3}$ found in pigmented GS samples, while the stronger band around 1033/ $\mathrm{cm}$ and double bands around 600 and $561.2 / \mathrm{cm}$ are due to phosphate [5]. From the FTIR study it can be concluded that spectrum of pigmented gallstone shows the characteristics IR band for bilirubin in the region between 1700 and $1500 / \mathrm{cm}$, the peak intensity $\sim 1600 / \mathrm{cm}$ is stronger in pigmented stone as compared to mixed and cholesterol stone, which shows that pigmented stones are rich in bilirubin. While the spectra of mixed and cholesterol stone indicates the presence of higher cholesterol content which is evident from the higher absorbance in the region between 3000 and $2800 / \mathrm{cm}$.

\subsection{Discussion of the results obtained}

The elemental analysis of understudy elements indicated that the concentration of Ca were slightly lowered in the serum samples of cholesterol and mixed GS patients while for pigmented GS patients it was found to be considerably higher than that of the control referents. Biliary Ca concentration was found to be higher in GS patients as compared to the control but the difference was significant for pigmented GS patients. The significant correlation of Ca between serum and bile, bile and stone samples of pigmented GS patients indicate that an increase in the concentration of $\mathrm{Ca}$ in the bile is secondary to an increase in its concentration in serum and hence an increase in the Ca contents of GS samples is secondary to an increase in its concentration in the bile of patients. The correlation study of Ca reveals its importance in the formation of pigmented GS.

The concentration of serum iron in the female patients having cholesterol GS was slight lowered than control, while in case of male cholesterol GS patient's serum Fe contents were comparable to that of control subjects. For pigmented and mixed GS patients the concentration of serum Fe were found to be higher than control subjects but significantly higher concentration of serum Fe were found for the pigmented GS patients. The contents of iron in bile sample of GS patients were found to be higher than control subjects but for pigmented GS 

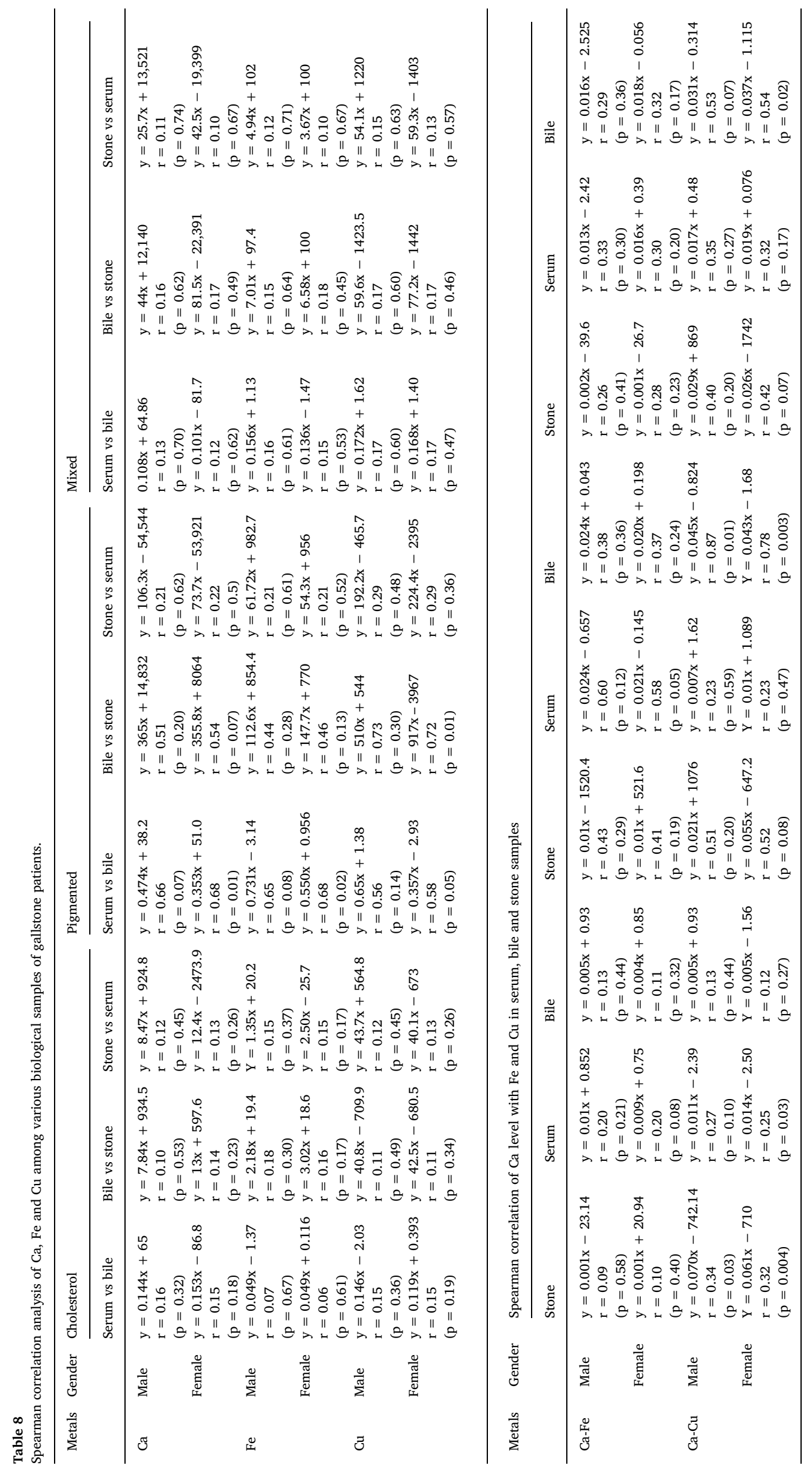
patients the biliary concentration of Fe were much more higher than that of the other two types of GS patients. The significant correlation of Fe (between serum and bile, bile and stone samples) in pigmented GS patients reveals that an increase in Fe concentration of serum is followed by an increase in biliary concentration of Fe which eventually precipitates into pigmented GS. This indicates an important role of Fe in the formation of pigmented GS. It is supported by our observation that Fe contents of the pigmented GS are several times greater than that of cholesterol and mixed GS.

The contents of $\mathrm{Cu}$ in serum samples of GS patients were found to be higher than control subjects but the difference was significant for the patients with pigmented GS. The biliary concentrations of $\mathrm{Cu}$ were found to be highly increased in GS patients as compared to control subjects. The significant correlation of $\mathrm{Cu}$ (between serum and bile, bile and stone samples) of pigmented GS patients indicate that the high concentration of $\mathrm{Cu}$ deposition in the pigmented GS are due to its increased concentration in the bile followed by their raised concentration in the serum. Beside significant correlation, a moderate correlation of the understudy elements exist between (serum and bile, bile and stone, serum and stone samples) of various patients having cholesterol and mixed GS. Which is understandable from the relatively low concentration of these metals in the cholesterol and mixed GS as compared to that of the pigmented GS.

Under normal circumstances the mucosal cells of gall bladder absorb certain amount of biliary $\mathrm{Ca}, \mathrm{Fe}$ and $\mathrm{Cu}$ which result into the low concentration of these metals in the bile of the gall bladder as compared to their concentrations in the serum. Undoubtedly this phenomena act as a remedy to lower the raised biliary concentrations of the cations which tend to facilitate crystallization of cholesterol in the gall bladder bile [18]. GS patients have raised concentrations of biliary Ca and other trace metals which appear to be due to the incapacity of the mucosal gall bladder cells to extract the surplus amount of these metals in the gall bladder bile. This is what we have find in our study that the mean bile concentration of $\mathrm{Ca}$ in controls subjects were lower than that of the GS patients but the difference was significant for the patients with pigmented GS as shown in the Table 8 . There is an agreement between the finding of ours and other researchers $[19,20]$.

Hepatic enzyme contain iron as a co-factor, variation in the concentrations of iron is associated with malfunctioning of hepatic enzymes responsible for cholesterol saturation in the bile and enhances cholesterol crystal formation in the gall bladder [21,22]. It is evident from the experimental studies that high dietary iron intake encourages lipid peroxidation and act as a fuel for the production of hydroxyl radicals which then causes the release of mucous glycoprotein in the gall bladder. Thus enhances the process of cholesterol crystallization in bile. Both hydroxyl radicals and mucous glycoprotein production in the gall bladder facilitate the materialization of GS in the gall bladder [23-25]. Moreover it is shown that the risk factors for gall stone like, alter blood lipids, higher ratio of saturated to unsaturated fatty acids and an increase concentration of plasma triacylglycerol are also related to high dietary iron intake [26-30]. The passage of $\mathrm{Cu}$ through bile from the liver is the prime way for the elimination of endogenous $\mathrm{Cu}$ and it is most probable for a person having an increased hepatic excretion of copper to develop gallstone [31]. The sources for high concentrations of endogenous $\mathrm{Cu}$ include, food being cocked in unlined copper cookware, hot water pipe, nutritional deficiencies tablet and contraceptive [32]. It was investigated that the formation of black pigment in gallstones occur due to the metallic elements, particularly $\mathrm{Ca}, \mathrm{Cu}$ and $\mathrm{Fe}$, which mostly form complexes with bilirubin [33]. Bile pigments act as ligands for some metals ions which can be attributed to be one of the reasons of their increased concentrations in the pigmented gallstones. Metalloenzymes abnormal catabolism can also lead to high amounts of metals in the GS [34].

To avoid the precipitation of Ca gall bladder mucosa secretes active hydrogen ions into the bile which keep the $\mathrm{pH}$ of bile low. Acidified bile plays a crucial role in the prevention of Ca precipitation [35]. It is reported in the literature that the development of GS in some patients may be caused due to the incapacity of mucosal membrane to secrete hydrogen ion into the bile [36]. This is what evident from our study that the bile of the patients having different types of GS was alkaline in nature as compared to the control subjects but for the patients with pigmented GS have a relatively higher alkaline bile as compared to the patients with cholesterol and mixed GS patients. Alkaline bile is known to facilitate the process of $\mathrm{Ca}$ and other trace elements which is understandable from the highly increased concentrations of these metals in the pigmented GS. Certain infection of the gall bladder mucosa also leads to the alkalinity of gall bladder bile [37].

The understudy metals were found in all types of GS. Ca is reported to be the main constituent of all types of GS [38]. In general pigmented GS contains highly increased concentration of $\mathrm{Ca}, \mathrm{Fe}$ and $\mathrm{Cu}$ as compared to that of cholesterol and mixed GS, The concentration of $\mathrm{Ca}, \mathrm{Fe}$ and $\mathrm{Cu}$ in different types GS were found in the decreasing order, Pigmented $>$ mixed $>$ cholesterol (Table 7). Other workers have also published similar results [39]. This may be due to the ability $\mathrm{Cu}$ and $\mathrm{Fe}$ to act as chelating agents for calcium bilirubinate.

\section{Conclusions}

Increased concentrations of biliary $\mathrm{Ca}, \mathrm{Cu}$ and $\mathrm{Fe}$ along with a relatively higher alkalinity and density of gall bladder bile in different types GS patients could be an important cause in the geniuses of GS especially in the patients with pigmented GS. The reduced capacity of the diseased gall bladder mucosa for the absorption of $\mathrm{Ca}$ and transition metals like ( $\mathrm{Cu}$ and $\mathrm{Fe}$ ), appears to be responsible of their higher concentration in bile. Pigment stones have a significantly higher content of $\mathrm{Ca}, \mathrm{Cu}$ and $\mathrm{Fe}$ than cholesterol and mixed GS. The distinction in gallstone composition including trace metal concentrations and other characteristics might be due to different geographical locations and dietary habits. $\mathrm{Fe}$ and $\mathrm{Cu}$ act as a promoter for cholesterol, pigmented and mixed GS formation. In the light of our findings, we recommend the detailed investigation of the promoter effect of $\mathrm{Fe}$ and $\mathrm{Cu}$ as well as the relatively higher density of bile in relation with understudy metals in gall stone patients especially in the patients with pigmented GS.

\section{Acknowledgments}

The authors would like to thank National Centre of excellence in analytical chemistry (NCEAC) University of Sindh Jamshoro for providing excellent research lab facilities for scholars to carryout research work. The author would also like to acknowledge administration of Mardan medical complex and teaching hospital Mardan (MMC) for their excellent cooperation to carry out this study.

\section{References}

[1] T.R. Rautray, V. Vijayan, S. Panigrahi, Analysis of Indian pigment gallstones, Nucl. Inst. Methods Phys. Res. B 255 (2007) 409-415.

[2] N. Ekinci, Y. Sahin, Determination of calcium and iodine in gall bladder stone using energy dispersive X-ray fluorescence spectrometry, Spectrochim. Acta B 57 (2002) 167-171.

[3] M.S. Ashok, N. Kalkupa, V.J. Kennedy, A. Markwitz, V. Jayanthi, K.G.M. Nair, V. Vijayan, Trace element analysis of south Indian gallstones by PIXE, Int. J. PIXE 12 (2002) 137-144.

[4] T.R. Rautray, V. Vijayan, S. Panigrahi, Analysis of Indian cholesterol gallstones by particle-induced X-ray emission and thermogravimetry-derivative thermogravimetry, Eur. J. Gastroenterol. Hepatol. 18 (2006) 999-1003.

[5] G. Liu, D. Xing, H. Wang, J. Wu, Vibrational spectroscopic study of human pigment gallstones and their insoluble materials, J. Mol. Struct. 616 (2002) 187-191.

[6] K. Szentmihalyi, P. Sipos, A. Blazovics, M. Szilágyi, Concentration of biliary metal elements and gallstone formation in humans (cholelithiasis), Trace Elem. Electrolytes 19 (2002) 160-164.

[7] S. Gokulakrishnan, M. Ashok, J. Jayanthi, Analysis of gallstone-a critical appraisal on various techniques, Gastroenterol. Today 5 (2001) 145-148.

[8] S.A. Arain, T.G. Kazi, H.I. Afridi, A.R. Abbasi, N. Ullah, A.H. Panhwar, S. Siraj, Determination of trace levels of iron in serum samples of hepatitis B and C patients using dispersive liquid-liquid microextraction, Anal. Methods 7 (2015) 9211-9217.

[9] S.A. Arain, T.G. Kazi, H.I. Afridi, A.R. Abbasi, J.A. Baig, A.H. Panhwar, N. Ullah, 
Solid phase microextraction of trace levels of copper in serum samples of hepatitis B patients, on activated carbon cloth modified with an ionic liquid by using a syringe mountable filter technique, J. Anal. At. Spectrom. 29 (2014) 2362-2370.

[10] P. Chandran, N.K. Kuchhal, P. Garg, C.S. Pundir, An extended chemical analysis of gallstone, Indian J. Clin. Biochem. 22 (2007) 145-150.

[11] U. Gupta, V.K. Singh, V. Kumar, Y. Khajuria, Experimental and theoretical spectroscopic studies of calcium carbonate $\left(\mathrm{CaCO}_{3}\right)$, Mater. Focus 4 (2015) 164-169.

[12] B.B.S. Jaswal, V. Kumar, H.C. Swart, J. Sharma, P.K. Rai, V.K. Singh, Multi-spectroscopic analysis of cholesterol gallstone using TOF-SIMS, FTIR and UV-Vis spectroscopy, Appl. Phys. B Lasers Opt. 121 (2015) 49-56.

[13] U. Gupta, V.K. Singh, V. Kumar, Y. Khajuair, Spectroscopic studies of cholesterol: Fourier transform infrared and vibrational frequency analysis, Mater. Focus 3 (2014) 211-217.

[14] B.B.S. Jaswal, K. Kumar, J. Sharma, P.K. Rai, M.A. Gondal, B. Gondal, V.K. Singh, Analysis of heterogeneous gallstones using laser-induced breakdown spectroscopy (LIBS) and wavelength dispersive X-ray fluorescence (WD-XRF), Lasers Med. Sci. 31 (2016) 573-579.

[15] X.S. Zhou, G.R. Shen, J.G. Wu, W.H. Li, Y.Z. Xu, S.F. Weng, R.D. Soloway, X.B. Fu, W. Tian, Z. Xu, T. Shen, G.X. Xu, E. Wentrup-Byrne, A spectroscopic study of pigment gallstones in China, Biospectroscopy 3 (1997) 371-380.

[16] O. Kleiner, J. Ramesh, M. Huleihel, B. Cohen, K. Kantarovich, C. Levi, B. Polyak, R.S. Marks, J. Mordehai, Z. Cohen, S. Mordechai, A comparative study of gallstones from children and adults using FTIR spectroscopy and fluorescence microscopy, BMC Gastroenterol. 2 (2002) 3.

[17] R.G. Raman, R. Selvaraju, FTIR spectroscopic analysis of human gallstones, Rom. J. Biophys. 18 (2008) 309-316.

[18] W.D. Neithercut, Effect of calcium, magnesium and sodium ions on in vitro nucleation of human gallbladder bile, Gut 30 (1989) 665-670.

[19] A.G. Auteri, C.L. Locke, D.F. Malet, Ionized calcium concentration is increased in gallbladder bile preceding black pigment gall stone formation in hamsters, Hepatology 10 (1989) 601.

[20] H.J. Sugarman, M.L. Shiffman, J.M. Kellom, E.W. Moore, Free calcium ions $\left(\mathrm{Ca}^{++}\right)$ are increased in gallbladder bile of patients with all types of gallstones, Hepatology 10 (1989) 601.

[21] J.J. Roslyn, R.L. Conter, E. Julian, M.Z. Abedin, The role of dietary iron in pigment gallstone formation, Surgery 102 (1987) 327-333.

[22] S.M. Johnston, K.P. Murray, S.A. Martin, K. Fox-Talbot, P.A. Lipsett, K.D. Lillemoe, H.A. Pitt, Iron deficiency enhances cholesterol gallstone formation, Surgery 122 (1997) 354-362.

[23] S. Brunet, L. Thibault, E. Delvin, W. Yotov, M. Bendayan, E. Levy, Dietary iron overload and induced lipid peroxidation are associated with impaired plasma lipid transport and hepatic sterol metabolism in rats, Hepatology 29 (1999) 1809-1817.

[24] M. Kadiiska, M.J. Burkitt, Q.H. Xiang, R.P. Mason, Iron supplementation generate hydroxyl radical in vivo. An ESR spin-trapping investigation, J. Clin. Invest. 96 (1995) 1653.

[25] M.I. Eder, J.F. Miquel, D. Jongst, G. Paumgartner, C. von Ritter, Reactive oxygen metabolites promote cholesterol crystal formation in model bile: role of lipid peroxidation, Free Radic. Biol. Med. 20 (1996) 743-749.

[26] P. Whittaker, R.F. Chanderbhan, Effect of increasing iron supplementation on blood lipids in rats, Br. J. Nutr. 86 (2001) 587-592.

[27] S.S. Jonnalagadda, E.A. Trautwein, A. Hayes, Dietary fats rich in saturated fatty acids (12: $0,14: 0$, and 16: 0 ) enhance gallstone formation relative to monounsaturated fats (18: 1) in cholesterol-fed hamsters, Lipids 30 (1995) 415-424.

[28] C.J. Tsai, M.F. Leitzmann, W.C. Willett, E.L. Giovannucci, The effect of long-term intake of cis unsaturated fats on the risk for gallstone disease in men: a prospective cohort study, Ann. Intern. Med. 141 (2004) 514-522.

[29] M. Fields, C.G. Lewis, Level of dietary iron, not type of dietary fat, is hyperlipidemic in copper-deficient rats, J. Am. Coll. Nutr. 18 (1999) 353-357.

[30] C.J. Tsai, M.F. Leitzmann, W.C. Willett, E.L. Giovannucci, Heme and non-heme iron consumption and risk of gallstone disease in men, Am. J. Clin. Nutr. 85 (2007) 518-522.

[31] V. Jain, A. Rai, P. Suryavanshi, H. Pahwa, S. Tiwari, D. Amla, Quantitative analysis of copper and zinc in gallstone patients, Int. J. Surg. 19 (2008) 1-4.

[32] B. Ashish, K. Neeti, K. Himanshu, Copper toxicity: a comprehensive study, Res J Recent Sci 2 (2013) 58-67.

[33] T. Koshinaga, Y. Koruso, K. Morita, T. Sasaki, S. Takeuchi, Analysis of metal concentrations in stones and bile of patients with pigment gallstones, Biomed. Res. Trace Elem. 2 (1991) 31-36.

[34] M. Ashok, T.R. Rautray, P.K. Nayak, V. Vijayan, V. Jayanthi, S.N. Kalkura, Energy dispersive X-ray fluorescence analysis of gallstones, J. Radioanal. Nucl. Chem. 257 (2003) 333-335.

[35] P.F. Malet, C.L. Locke, B.W. Trotman, R.D. Soloway, The calcium ionophore A23187 stimulates glycoprotein secretion by the guinea pig gallbladder, Hepatology 6 (1986) 569-573.

[36] T.H. Magnuson, K.D. Lillemore, G.E. Peoples, H.A. Pitt, Oral calcium promotes pigment gallstone formation, J. Surg. Res. 46 (1989) 286-291.

[37] G. Horn, Observation on the etiology of cholelithiasis, Br. Med. J. 2 (1956) 732.

[38] K. Saito, S. Kanno, Y. Shimada, K. Nakadate, Trace metal elements in gallstones and their roles, Nippon Rinsho Jpn. J. Clin. Med. 51 (1993) 1725-1730.

[39] N. Suzuki, Y. Nakamura, N. Kobayashi, T. Sato, On metal elements in pure pigment stones, Tohoku J. Exp. Med. 116 (1975) 223-240. 